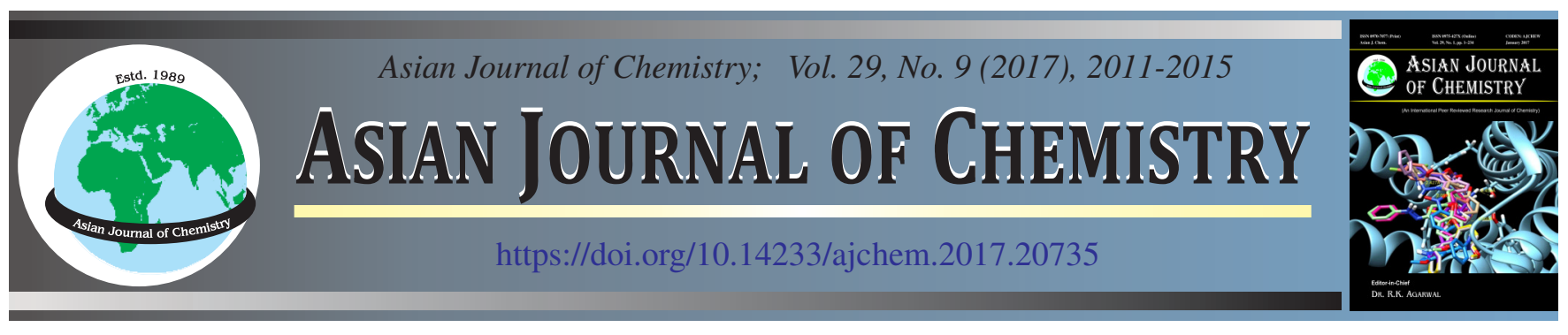

\title{
Mineral Composition, Physico-chemical Properties and Fatty Acids Profile of Prunus armeniaca Apricot Seed Oil
}

\author{
Nabi Shariatifar ${ }^{1}$, IsSa Mohammad Pourfard ${ }^{1, *}$, Gholamreza Jahed Khaniki ${ }^{1}$, \\ Ramin Nabizadeh ${ }^{1}$, Arash Akbarzadeh and Amir SaSan Mozaffari Nejad ${ }^{2,3, *}$
}

\author{
${ }^{1}$ Department of Environmental Health Engineering, School of Public Health, Tehran University of Medical Sciences, Tehran, Iran \\ ${ }^{2}$ Nutrition Health Research Center, Hamadan University of Medical Sciences, Hamadan, Iran \\ ${ }^{3}$ Department Microbiology, Osmania University, Hyderabad-500 007, India
}

*Corresponding authors: Fax: +98 8138380130; Tel: +98 8138380755; E-mail: Isamohammadpour@yahoo.com; asmozafarinejad@yahoo.in

Apricot (Prunus armeniaca L.) kernel oil is obtained from the kernels (seeds) of apricots. This research aimed to investigate the physicochemical properties of wild apricot kernel oil. The apricot oils tested in this study showed a high content of unsaturated and low saturated fatty acids. Significant differences existed between the physico-chemical indices of different wild apricot kernel oil. The meaning of peroxide value (meq/kg), acid value, iodine value and saponification number of wild apricot kernel oil were $0.67375,0.48625,100.27$ and 1089.06, respectively. The mean rate of oil contents in wild apricot kernels varied from 38 to $55.3 \%$. Oleic acid (60.01-70.56\%) is the key fatty acid found in wild apricot kernel oil, followed by linoleic acid (19.74-23.52 \%) and palmitic acid (2.35-5.97 \%). The results showed that the physical and chemical characteristics of apricot kernel oil samples were favourable for edible and pastry industry.

Keywords: Apricot, Kernel, Oil, Physico-chemical properties.

\section{INTRODUCTION}

Edible oils are an important food source for humans because they supply essential fatty acids such as linoleic acid. Oils are also used in the cosmetics and pharmaceutical industries. The oils obtained from plant seeds can be both edible and non-edible relating on the plant source. These oils are often available as raw materials for food industry usage. Because of the high request and economic aspects of these oils to the chemical industry, attention has been focused on the under utilized Prunus armeniaca $L$. kernel for possible development and use [1,2].

Some studies have been conducted to assess the physical as well as chemical properties of the apricot seeds. Alpaslan and Hayta [3] have showed the physical and chemical composition of Turkish apricot kernels. Gezer et al. [4] has showed some physical properties of apricot pit and kernel of Turkish apricot kernels. Ozcan et al. [5] have reported the same physical properties of apricot kernel oil of Turkish Prunus armeniaca $L$. of oil. However, no study has been done about Iranian wild apricot kernel oil. Kernels of apricot, peach and plum are produced as byproducts by the food canning industry [4-8]. This not only wastes a potentially economically-valuable resource, but also aggravates an already serious disposal problem. For these reasons, both the oil and kernel from these fruit seeds should be utilized [2].

The pits are considered as potential sources of oils [4]. Apricot kernels contain essential amino acids and high concentrations of potassium and magnesium minerals, B group vitamins and oil; its oil is high in unsaturated fatty acids, especially oleic acid (31-80\%) and linoleic acid (6.3-51\%) [9,10]. The apricot is a member of the Rosaceae family, which found in regions including Iran, Pakistan, USA, Turkey, Spain, Africa, Australia, Morocco, Italy, France and Russia [9,11].

In the present study, oil was extracted from the seed of Iranian Prunus armeniaca $L$. by hexane solvent method and the fatty acid, mineral contents of the oil and seed compounds of Prunus armeniaca $L$. were determined. Although some work has been performed to determine the fatty acid composition of Prunus armeniaca $L$. seed oil from Pakistan, India and Turkey [3-5,9]. It was the first time Iranian Prunus armeniaca $L$. oil extracted with hexane solvent method was investigated and mineral contents of wild Prunus armeniaca L. seed oil were determined.

\section{EXPERIMENTAL}

Apricot seed samples were obtained from the fruits of the main Prunus armeniaca L. which were picked by hand during 
the crop season 2013 (June-July). All kernel samples were kept at the refrigerator temperature $\left(4^{\circ} \mathrm{C}\right)$ until their use in the experiments. The chemicals and solvent used in this study were of analytical grade and purchased from Merck (Germany).

Extraction of seed oil: Oil samples were extracted from apricot seeds by Soxhlet extraction using $n$-hexane ( $15 \mathrm{~g}$ seed powder with $250 \mathrm{~mL} n$-hexane) with a temperature ranging from 60 to $80^{\circ} \mathrm{C}$ for $8 \mathrm{~h}$. The $n$-hexane was then removed with a rotary vacuum evaporator [12]. The pure oils were transferred into dark-coloured glass vials, which were flushed with nitrogen before storage (to decrease oxidation). Samples were maintained at $-18{ }^{\circ} \mathrm{C}$ until analysis.

Analysis of apricot kernel oil: The physico-chemical properties of apricot kernel oil including acid value (AV), iodine value (IV), saponification value (SV), peroxide value (PV), protein content, moisture, ash and free fatty acids were determined according to previously-reported methods (AOAC).

Mineral ions in the extracted oils were prepared and samples were filtrated through Whatman ${ }^{\circledR}$ No. 42 . The filtrates were collected in $50 \mathrm{~mL}$ Erlenmeyer flasks and analyzed by ICPAES Varian) according to the method of Pehlivan et al. [13] with some modification and also similar methods were also described by William [14] and Kamkar et al. [15].

Determination of fatty acids: Fatty acid methyl esters of the extracted oils were prepared according to the method of Metcalfe et al. [16] with some modification. Gas chromatography (GC) analyses were performed with a Varian GC coupled with a $\mathrm{BP} \times 70$ fused silica capillary column $(60 \mathrm{~m} \times$ $0.25 \mathrm{~mm}$ ID and $0.35 \mu \mathrm{m}$ film thicknesses) using nitrogen as a
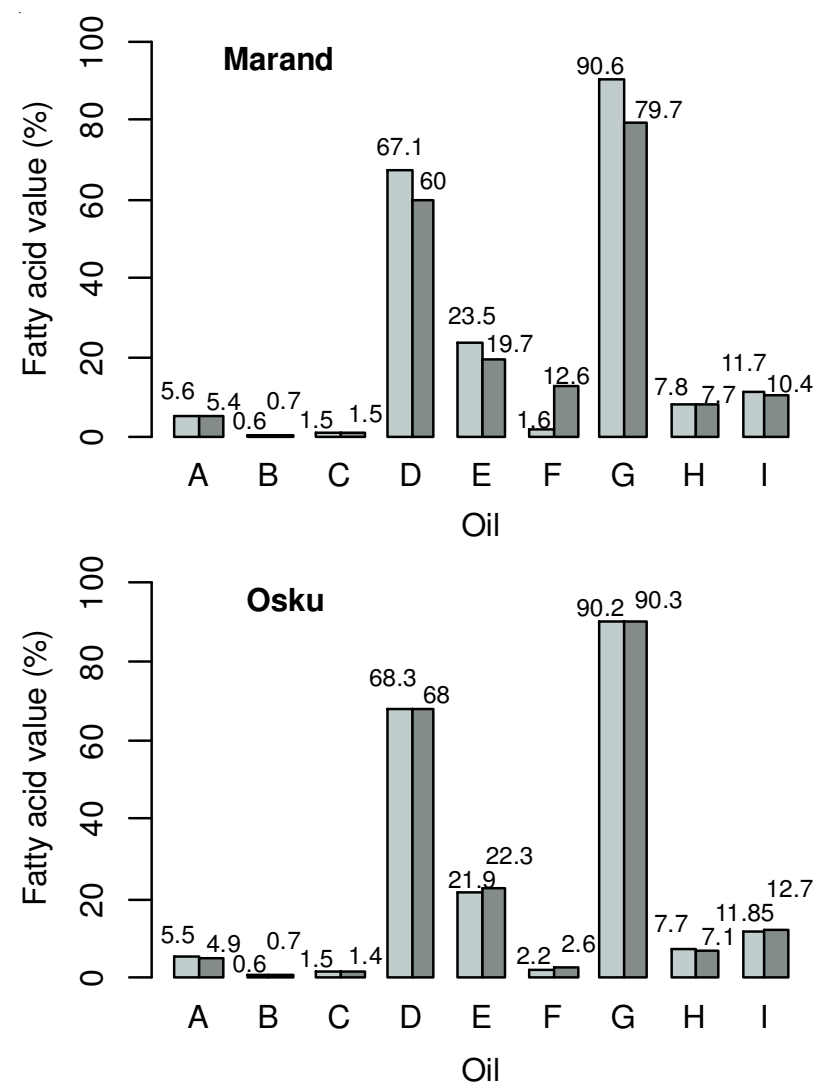

carrier gas. The oven temperature program was as follows: $60{ }^{\circ} \mathrm{C}$ for $5 \mathrm{~min}$; heat to $180{ }^{\circ} \mathrm{C}$ for $4{ }^{\circ} \mathrm{C} / \mathrm{min}$; hold for $15 \mathrm{~min}$; and heat to $215^{\circ} \mathrm{C}$ for $4{ }^{\circ} \mathrm{C} / \mathrm{min}$. The temperatures of the injector and temperature detector were 250 and $280{ }^{\circ} \mathrm{C}$, respectively.

Statistical analysis: All analyses are triplicate determinations. Result values are expressed as mean \pm standard deviation of triplicate determinations. All analyses were done by Statistical Software. $\mathrm{P}$ values were considered significant when $\mathrm{P}<0.05$.

\section{RESULTS AND DISCUSSION}

Gas chromatography analyses of the fatty acid content of apricot kernel oil showed that the oils contain oleic acid, linoleic acid, palmitic acid, stearic acid, palmitoleic acid and linolenic acid. Oleic acid contents ranged from 60.0 to $70.6 \%$, while linoleic acid contents ranged from $19.7 \%$ (Marand bitter) to $23.5 \%$ (Marand sweet) (Fig. 1). Oil extracted from apricot kernel oil is pale yellow, free of sediments and tasteless. It is liquid at room temperature (between 59 and $86^{\circ} \mathrm{F}$ ). The oil yield of Bonab bitter and Osku sweet were 38 and $55.3 \%$, respectively. Determined content ranges were $17.8 \%$ (Osku sweet) to $23.4 \%$ (Bonab bitter) for protein, $2.1 \%$ (in Osku sweet) to $3.4 \%$ (Bonab bitter) for ash and $4.2 \%$ (Maraghe bitter) to $5.3 \%$ (Marand sweet) (Fig. 2). The moisture, iodine, acid, peroxide and saponification values of the extracted oils ranged from 90.3 (Marand bitter) to 103.9 (Marand sweet), 0.2 (Bonab sweet) to 0.6 (Osku bitter), 0.35 (Maraghe bitter) to 1.9 (Osku bitter) and 183.3 (Maraghe bitter) to 195.5 (Bonab bitter) (Fig. 3). The content of mineral ions in the kernel samples is shown in Fig. 4. Phosphorus has the highest mean
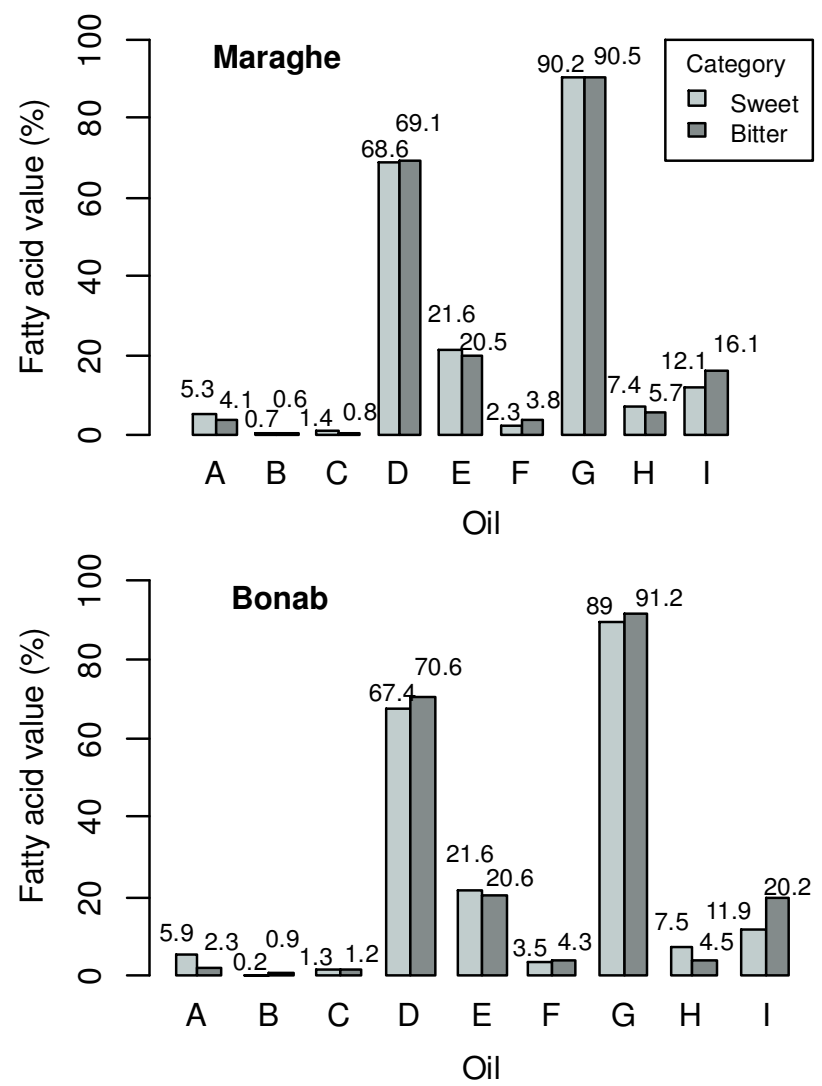

Fig. 1. Fatty acid compositions of sweet and bitter apricot kernel oils (\%); Palmitic acid (A), Palmitoleic acid (B), Stearic acid (C), Oleic acid (D), Linoleic acid (E), Other fatty acid (F), USFA* (G), SFA** (H), USFA/SFA (I). *USFA = unsaturated fatty acid, **SFA = saturated fatty acid 

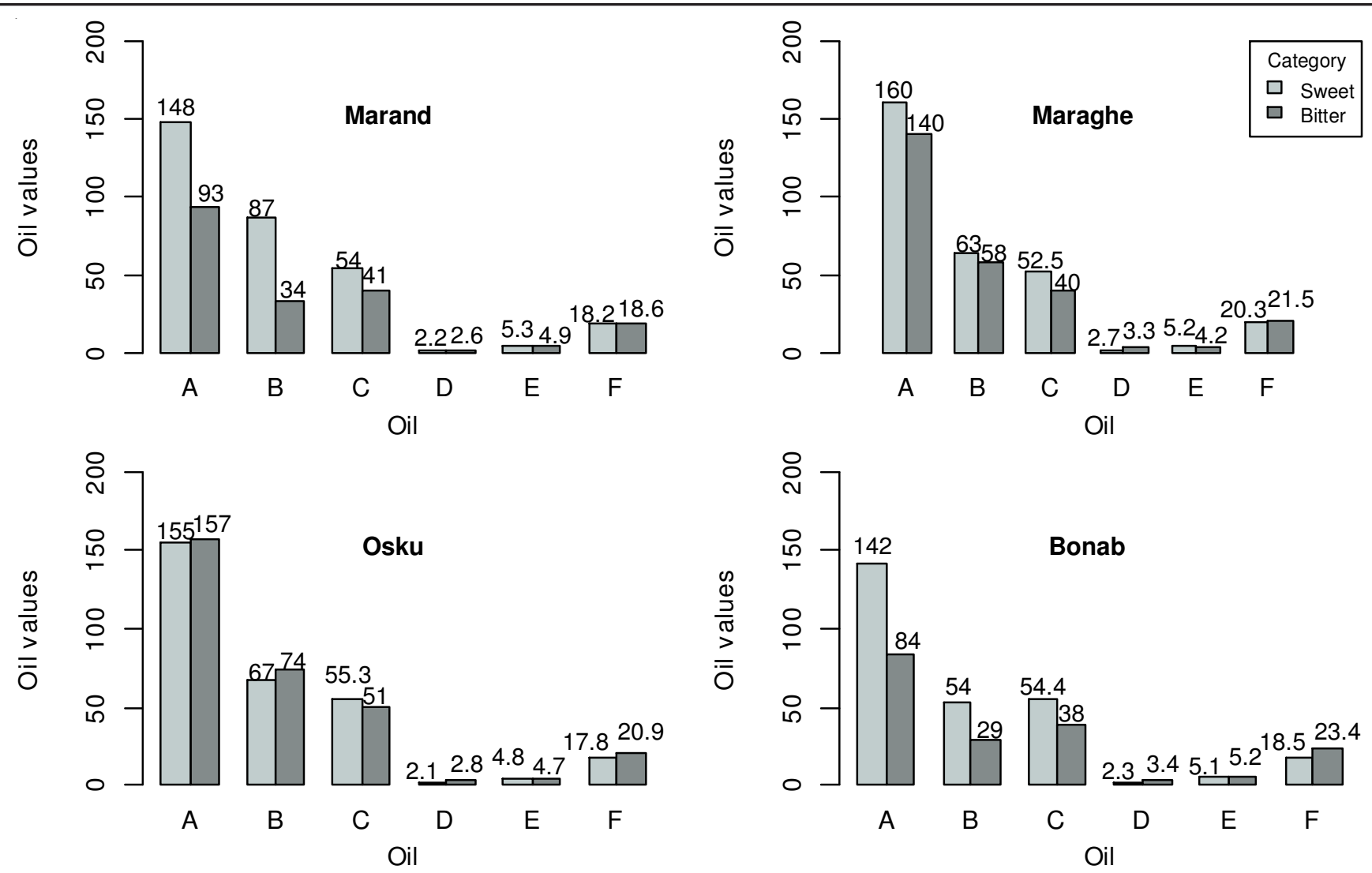

Fig. 2. Proximate composition of sweet and bitter apricot kernel oils (g/100 g); Weight kernel* (A), Weight seed** (B), Yield ( \%) (C), Ash (\%) (D), Moisture (\%) (E), Protein (\%) (F). *Weight kernel (The number of 100 kernels) **Weight seed (The number of 100 seeds)

concentration, while cobalt is present in the smallest detectable concentration.

Unsaturated vegetable oils, including apricot oil, may be able to reduce low-density lipoprotein (LDL) serum cholesterol levels. The use of saturated vegetable oils including hydrogenated oils can be a factor in raising low-density lipoprotein levels and decreasing high-density lipoprotein levels in the blood, which can increase the risk of blood clotting (inside the blood vessels). Today, the use of unsaturated vegetable oils is recommended by the medical community. Also, some researchers demonstrated that they are a promising source of antimicrobial agents [17-20]. The oils of both Bonab bitter and Maraghe bitter apricots are superior to other oils in terms of their nutritional value owing to their oleic acid profiles. Apricot kernel oil at room temperature is liquid, as are all other routinely used edible oils [21]. Moisture content in oils ranged from 4.1 to $5.3 \%$. The moisture content of the sample seed oils in this study is generally low, indicating that the seed oils could be stored for long periods of time.

Saponification number of all wild apricot kernel oil samples ranged from $183.3 \mathrm{mg} \mathrm{KOH} / \mathrm{g}$ to $195.5 \mathrm{mg} \mathrm{KOH} / \mathrm{g}$. The saponification value is an indicator that can be used to compare relative molecular masses and indicate the usefulness of oil in the industry. It depends on the average molecular weight or fatty acid chain length of all the fatty acids present, this value indicate that the oils have smaller molecular weight $[22,23]$. The oil yield of wild apricot kernels in this study ranged from 38 to $55.3 \%$, which is similar to the range reported for other commonly used edible oils.
Acid value is an indicator of the suitability of oil edibility for industrial use. Apricot kernel oil had acid values ranging from 0.2 to 0.6 , which is nearest to the range observed in almond seed oil [24,25]. The iodine value of the apricot oil was highest for the Marand bitter (103.9) cultivar; the minimum amount was found in the oil of the Marand sweet (90.3) cultivar. These values suggest that apricot kernel oil is suitable for edible purposes, as well as pastry and cosmetic applications [26]. The apricot kernel oil has approximately the same ratio of saturated to unsaturated fatty acid as edible oils such as canola oil, corn oil, linseed oil, safflower oil and almond oil. Owing to these chemical properties, the apricot kernel oil may be a good replacement for olive oil in industrial, cosmetic and food applications [27-31]. The apricot kernel oil also has almost the same mineral composition as the conventional seed oils from other plant sources. It is rich in phosphorous, copper, zinc, iron and potassium, making it suitable for health and commercial uses.

The physico-chemical properties of oils depend on two groups of fatty acids: saturated and unsaturated. Fatty acid composition of wild apricot kernel oil is similar to almond seed oil $[10,25]$. In the present study, apricot kernel oil is characterized by the presence of six major fatty acids e.g., oleic, linoleic, palmitic, stearic, palmitoleic and linolenic acids. Together these fatty acids composed more than $95 \%$ of the total fatty acid content. A previous study reported that bitter apricot kernel oils have high fatty acid contents. Similar results were observed in previous study [6]. Bachheti et al. [11] revealed that the apricot kernel oil contains oleic acid $(73.58 \%)$, 

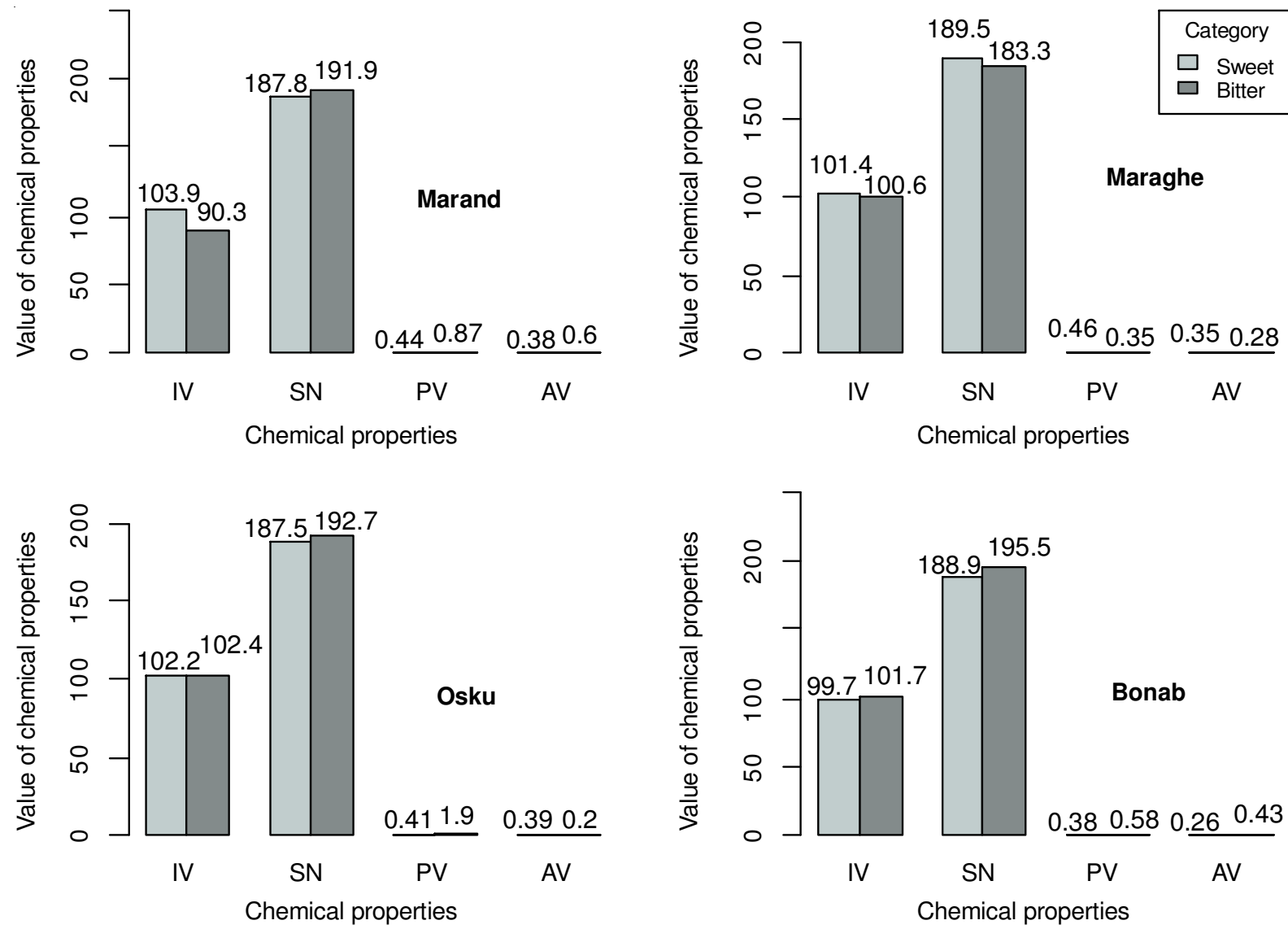

Fig. 3. Chemical properties of some common sweet and bitter apricot kernel oils; (1) Iodine value (g $\mathrm{I}_{2}$ per $100 \mathrm{~g}$ of oil), (2) Saponification number (mg KOH per g of oil), (3) Peroxide value (mequiv $\mathrm{O}_{2}$ per $\mathrm{kg}$ of oil), (4) Acid value (mg KOH per g of oil)
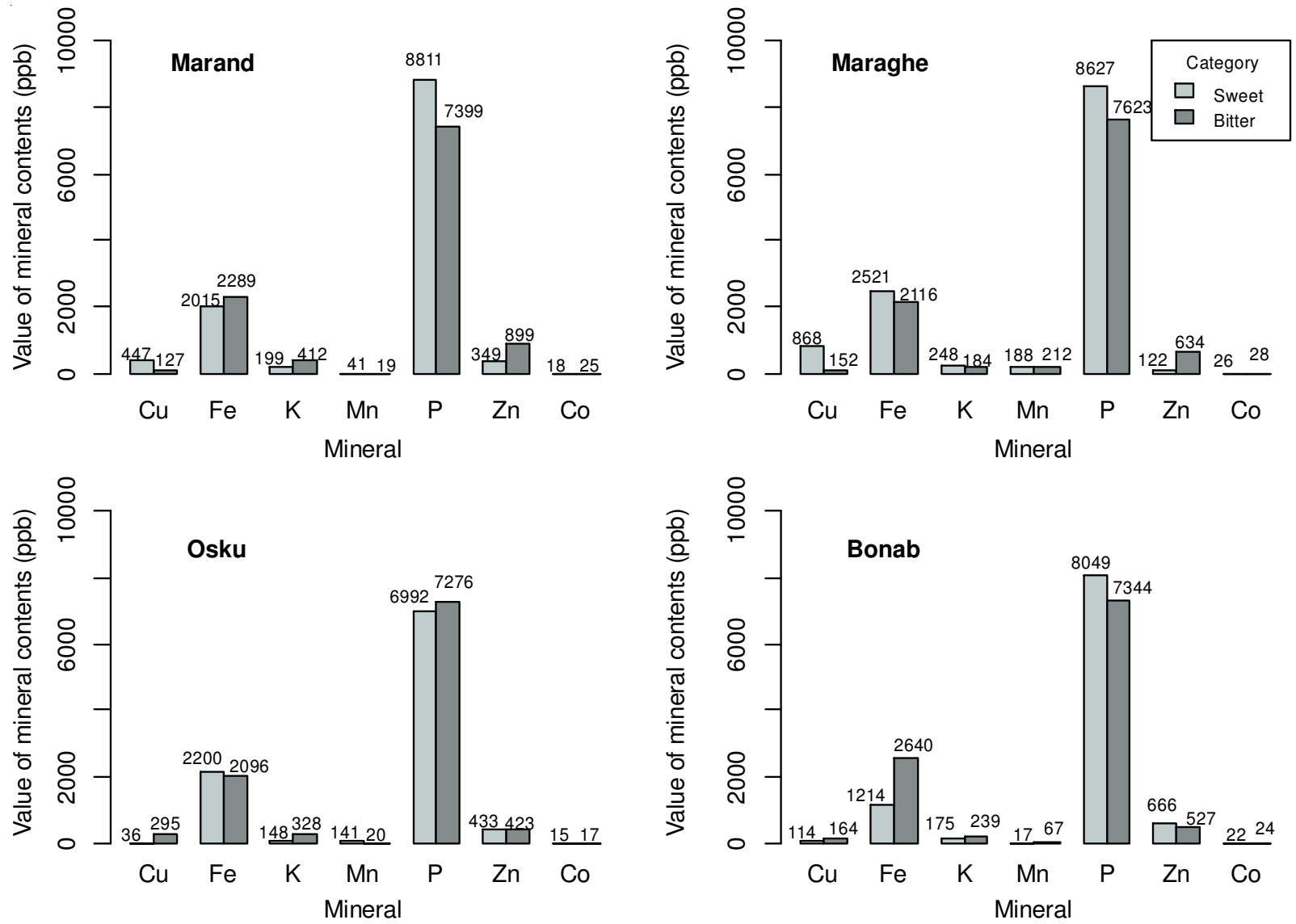

Fig. 4. Mineral contents (ppb) of sweet and bitter apricot kernel oils 
linoleic acid $(19.26 \%)$, palmitic acid $(3.31 \%)$ and stearic acid $(2.68 \%)$; similar oil compositions were determined in our research study. Ali et al. [32] reported that the crude protein (6.18-8.7\%), crude fat (2.1-3\%), ash (9.45-12.1\%), crude fiber (11.85-13.6\%) and total sugars (56.8-64.9\%), determined on a dry weight basis. In this respect, their study is dissimilar to the present study. Ozcan et al. [5] showed that the major fatty acids in apricot kernel oils were oleic acid, linoleic acid and palmitic acid. The oleic acid content of kernel oils varied between 53.06 and $70.90 \%$, while linoleic acid contents ranged between 21.43 and $35.67 \%$. In this respect, their results were similar to the present study's findings.

\section{Conclusion}

In conclusion, the results of this study combined with previously reported findings show that apricot kernels contain a high percentage of unsaturated fatty acids. Oils containing small amounts of saturated fatty acids and large amounts of monounsaturated fatty acids are highly favoured in the human diet. Apricot kernels have high oil yields (> $50 \%$ ), which is comparable to the oil yield of some commercial seed oils. The results obtained from this study can be used as baseline facts to develop apricot kernel oil for both domestic and industrial purposes. They can also be used to promote the sustainable cultivation of the apricot tree in the mountain region of Iran for large-scale oil production.

\section{ACKNOWLEDGEMENTS}

The authors thank Tehran University of Medical Sciences for providing all of the support for this study. Thanks are also due to Mr. Nazmara and Mrs. Shiri for their technical help.

\section{REFERENCES}

1. B. Adinew, Bulg. Chem. Commun., 46, 330 (2014).

2. I. Hussain, S. Gulzar and I. Shakir, Int. J. Food Safety, 13, 11 (2011).

3. M. Alpaslan and M. Hayta, J. Am. Oil Chem. Soc., 83, 469 (2006); https://doi.org/10.1007/s11746-006-1228-5.

4. I. Gezer, H. Haciseferogullari and F. Demir, J. Food Eng., 56, 49 (2003); https://doi.org/10.1016/S0260-8774(02)00147-4.

5. M.M. Ozcan, C. Ozalp, A. Unver, D. Arslan and N. Dursun, Food Nutr. Sci., 1, 31 (2010); https://doi.org/10.4236/fns.2010.12006.

6. M.M. Hassanein, Grasas Aceites, 50, 379 (1999); https://doi.org/10.3989/gya.1999.v50.i5.682.

7. B. Kamel and Y. Kakuda, J. Am. Oil Chem. Soc., 69, 492 (1992); https://doi.org/10.1007/BF02540957.

8. K. Sharma, R. Sharma and S. Attri, Indian J. Nat. Prod. Resour, 2, 409 (2011).
9. A. Gupta, P. Sharma, B. Tilakratne and A.K. Verma, Indian J. Nat. Prod. Resour., 3, 366 (2012).

10. E.S. Lazos, Grasas Aceites, 42, 127 (1991); https://doi.org/10.3989/gya.1991.v42.i2.1260.

11. R.K. Bachheti, I. Rai, A. Joshi and V. Rana, Int. Food Res. J., 19, 577 (2012).

12. Q.-A. Zhang, Z.-Q. Zhang, X.-F. Yue, X.-H. Fan, T. Li and S.-F. Chen, Food Chem., 116, 513 (2009); https://doi.org/10.1016/j.foodchem.2009.02.071.

13. E. Pehlivan, G. Arslan, F. Gode, T. Altun and M.M. Özcan, Grasas Aceites, 59, 239 (2008); https://doi.org/10.3989/gya.2008.v59.i3.514.

14. H. William, Official Methods of Analysis of AOAC International, edn 17, p. 481 (2000).

15. A. Kamkar, M.R.S. Ardekani, N. Shariatifar, A. Misagi, A.S.M. Nejad and A.H. Jamshidi, S. Afr. J. Bot., 85, 39 (2013); https://doi.org/10.1016/j.sajb.2012.12.001.

16. L. Metcalfe, A.A. Schmitz and J. Pelka, Anal. Chem., 38, 514 (1966); https://doi.org/10.1021/ac60235a044.

17. S.M. Grundy, N. Engl. J. Med., 314, 745 (1986); https://doi.org/10.1056/NEJM198603203141204.

18. M. Eslami, M. Bayat, A.S. Mozaffari Nejad, A. Sabokbar and A.A. Anvar, Saudi J. Biol. Sci., 23, 341 (2016); https://doi.org/10.1016/j.sjbs.2015.07.004.

19. A.S. Mozaffari Nejad, M. Bayat and A.A. Ahmadi, J. Pure Appl. Microbiol., 7, 3219 (2013).

20. A.S. Mozaffari Nejad, S. Shabani, M. Bayat and S.E. Hosseini, Jundishapur J. Microbiol., 7, e13134 (2014); https://doi.org/10.5812/jim.13134.

21. S. Liu, F. Yang, C. Zhang, H. Ji, P. Hong and C. Deng, J. Supercrit. Fluids, 48, 9 (2009); https://doi.org/10.1016/j.supflu.2008.09.013.

22. A. Tautua, B. Martin W and O. Adebayo, Pak. J. Nutr., 12, 647 (2013); https://doi.org/10.3923/pjn.2013.647.650.

23. F. Van de Voort, J. Sedman, G. Emo and A. Ismail, J. Am. Oil Chem. Soc., 69, 1118 (1992); https://doi.org/10.1007/BF02541047.

24. A. Joshi, P. Singhal and R. Bachheti, Int. J. Chemtech Res., 5, 2993 (2013).

25. A. Moayedi, K. Rezaei, S. Moini and B. Keshavarz, J. Am. Oil Chem. Soc., 88, 503 (2011); https://doi.org/10.1007/s11746-010-1701-z.

26. S. Johnson, N. Saikia, H.B. Mathur and H.C. Agarwal, Fatty Acids Profile of Edible Oils and Fats in India, Centre for Science and Environment, Report No. CSE/PML/PR-32/2009, pp. 1-33 (2009).

27. B. Cosge, B. Gurbuz and M. Kiralan, Int. J. Nat. Eng. Sci., 1, 11 (2007).

28. R. Farhoosh and J. Tavakoli, J. Food Lipids, 15, 433 (2008); https://doi.org/10.1111/j.1745-4522.2008.00131.x.

29. J.-S. Kwon, J.T. Snook, G.M. Wardlaw and D.H. Hwang, Am. J. Clin. Nutr., 54, 351 (1991).

30. R.D. O'Brien, Fats and Oils: Formulating and Processing for Applications, CRC Press, edn 3 (2010).

31. J. Sebedio, J. Prevost and A. Grandgirard, J. Am. Oil Chem. Soc., 64, 1026 (1987); https://doi.org/10.1007/BF02542443.

32. S. Ali, T. Masud and K.S. Abbasi, Sci. Hortic., 130, 386 (2011); https://doi.org/10.1016/j.scienta.2011.05.040. 